\title{
Journal of Melittology
}

Bee Biology, Ecology, Evolution, \& Systematics

The latest buzz in bee biology

No. 27, pp. 1-6

18 January 2014

Journal of Melittology: First year 'abuzz'

Michael S. Engel ${ }^{1}$, Victor H. Gonzalez ${ }^{1,2}$, \& Charles D. Michener ${ }^{1}$

Abstract. The Journal of Melittology celebrates its first year of activity. In total 26 articles were published comprising 243 pages, and including accounts historical and biographical interest, biological and biogeographic notes, and the description of 19 new species, two new subgenera, and three new genera in 2013.

This year, on the $11^{\text {th }}$ of January, we celebrated the first anniversary of the Journal of Melittology (JoM). What many years earlier started as a dream, today it is materialized in an open-access journal dedicated to melittological research. A total of 26 articles, each published as its own issue and accounting for 243 pages total, went on to print last year. This means, on average two papers were published each month thanks to the contributions of 23 authors located in the U.S.A., Canada, Colombia, Chile, Argentina, India, and Denmark. About $70 \%$ of the papers were on several aspects of the systematics of both living and extinct taxa. A total of three genera (Engel \& Michener, 2013; Gonzalez et al., 2013b, 2013c), two subgenera (Engel, 2013e; Engel et al., 2013b), and 19 species were published, including four fossil species and five cleptoparasites (Engel, 2013b, 2013c, 2013d, 2013e; Engel \& Breitkreuz, 2013; Engel \& Packer, 2013; Engel \& Rasmussen, 2013; Gibbs \& Dumesh, 2013; Griswold, 2013; Sheffield \& Genaro, 2013) (Table 1) (Figs. 1-6). All names were registered in ZooBank and the journal itself is being archived in Portico, thus in compliance with the latest standards of the International Code of Zoological Nomenclature. In addition, a small number of copies of each issue are printed by the Southwestern Oklahoma State University Press in high quality, acid-free paper, which will be archived in our institution's libraries. The same high quality printings are available to authors at cost, if they desire reprints of their papers

\footnotetext{
${ }^{1}$ Division of Entomology, Natural History Museum, and Department of Ecology \& Evolutionary Biology, 1501 Crestline Drive - Suite 140, University of Kansas, Lawrence, Kansas 66045, USA (msengel@ku.edu, michener@ku.edu).

${ }^{2}$ Department of Biological Sciences, Southwestern Oklahoma State University, 100 Campus

Drive, Weatherford, Oklahoma 73096, USA (victorgonzab@gmail.com).
} 


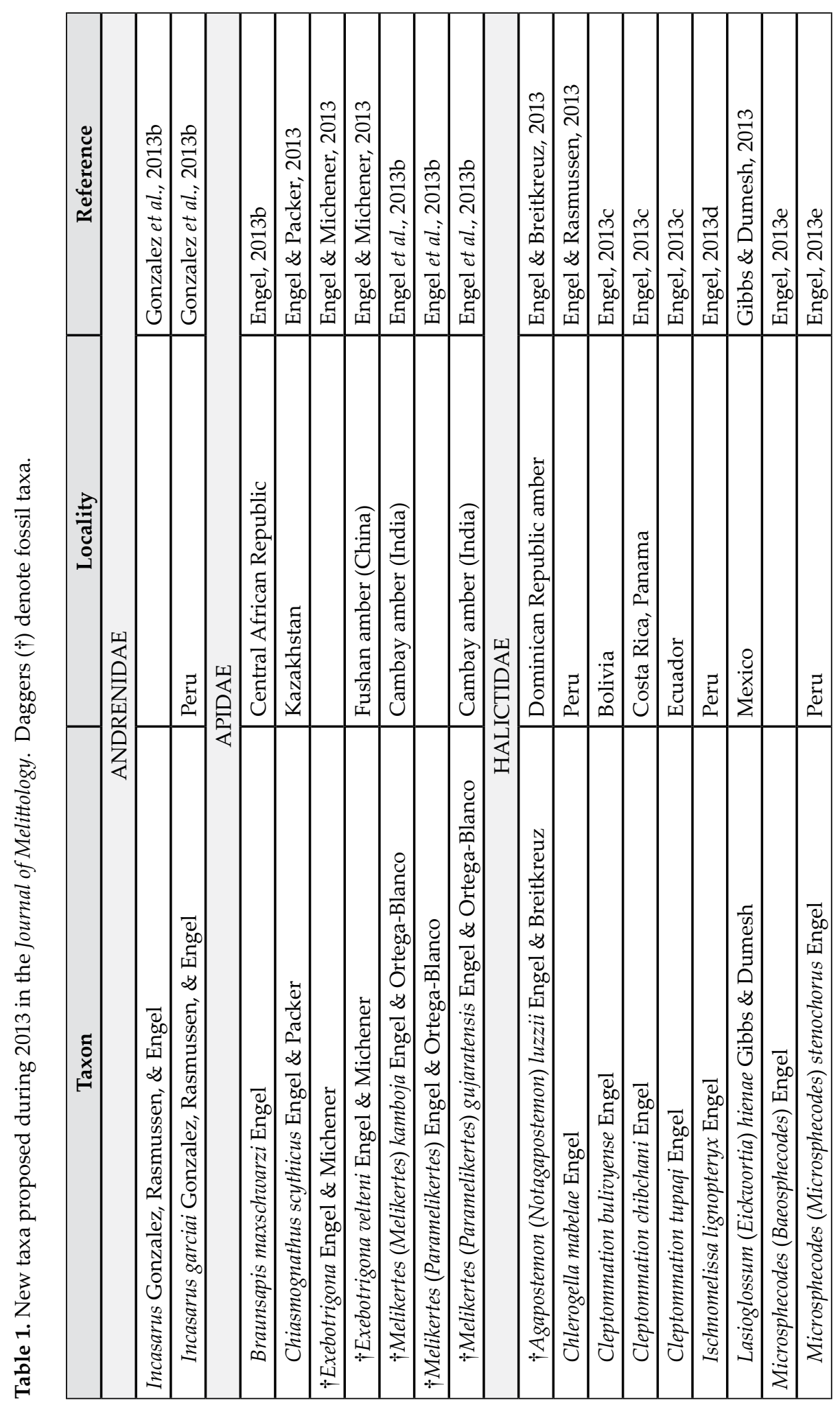




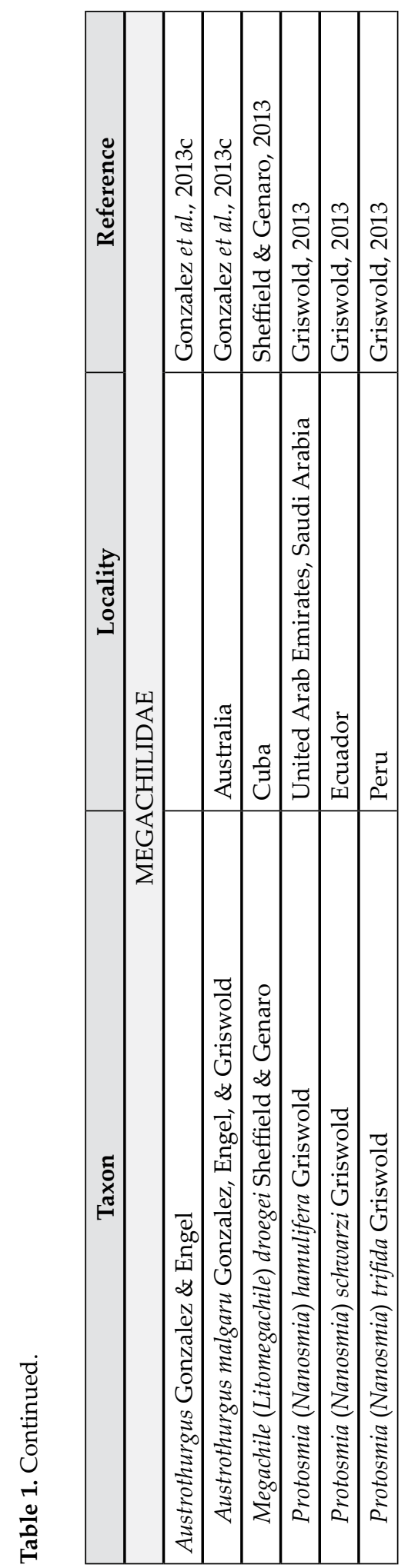



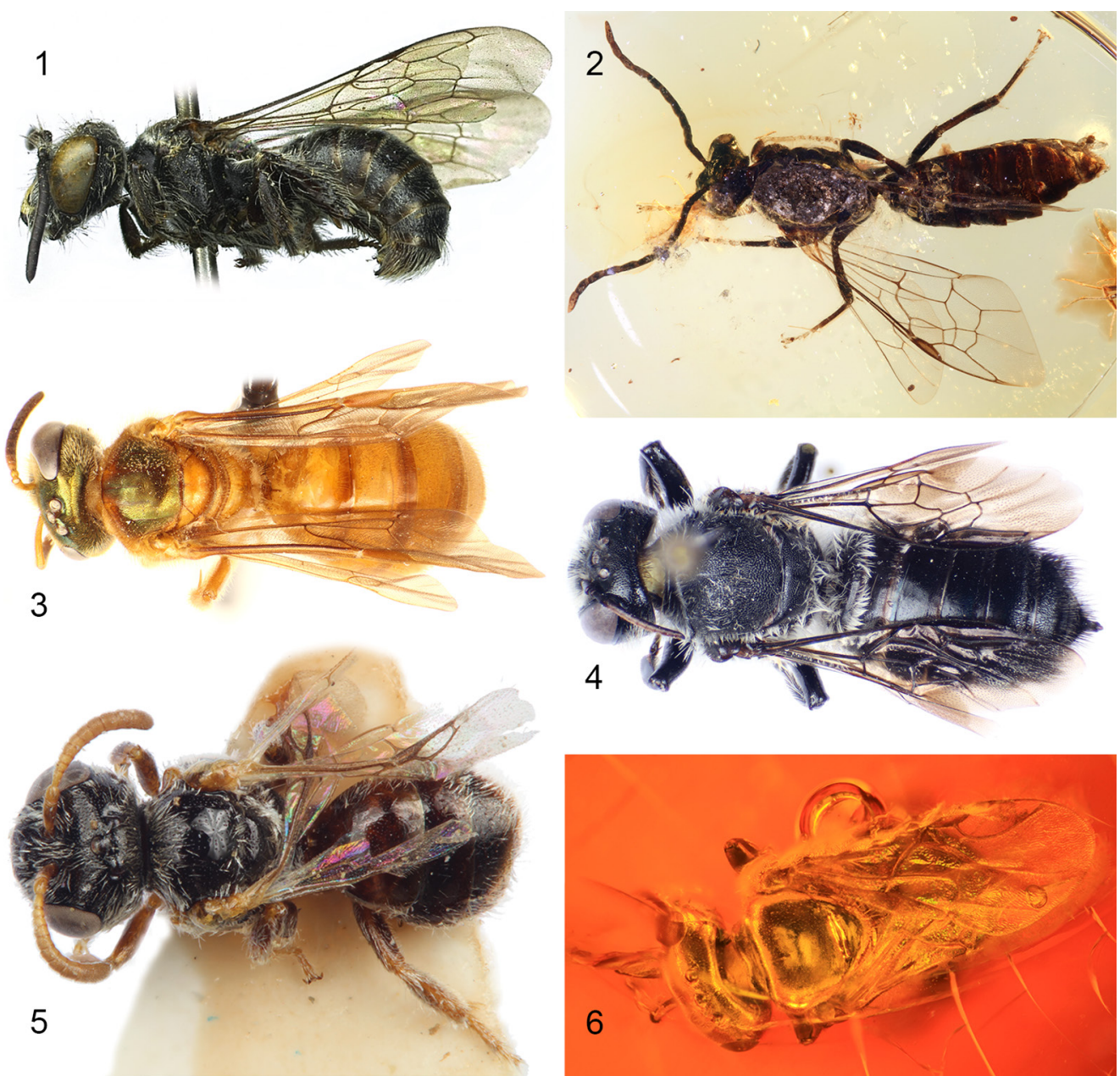

Figures 1-6. Representative taxa presented in the Journal of Melittology during 2013. 1. Incasarus garciai Gonzalez, Rasmussen, \& Engel (Andrenidae: Panurginae). 2. † Agapostemon (Notagapostemon) luzzii Engel \& Breitkreuz (Halictidae: Halictinae). 3. Cleptommation chibchani Engel (Halictidae: Halictinae). 4. Austrothurgus malgaru Gonzalez, Engel, \& Griswold (Megachilidae: Lithurginae). 5. Chiasmognathus scythicus Engel \& Packer (Apidae: Nomadinae). 6. †Exebotrigona velteni Engel \& Michener (Apidae: Apinae).

(as 'print on demand'). Individual articles and citations to those papers are also tracked by Google Scholar, pushing the journal's message into the global academic community. The remaining papers were contributions to the biology of bees and contained information on foraging behavior, geographic distribution, biogeography, morphology, paleoentomology, and pollination (Hinojosa-Díaz, 2013; Gonzalez, 2013; Gonzalez et al., 2013a; Michener, 2013; Montalva et al., 2013; Rathor et al., 2013; Velez-Ruiz et al., 2013; Zambrano et al., 2013). Species from nearly all living bee families were directly or indirectly treated in the articles last year, and although not surprising, about half of the contributions were on taxa of the megadiverse family Apidae. Beyond these, two issues were biographic accounts of prominent melittologists (Gonzalez \& Engel, 2013; Rasmussen et al., 2013), one a historical note on bees in ancient literature (Engel, 2013a), and one our inaugural paper introducing JoM itself (Engel et al., 2013a). 
The publishing rate as well as the topics covered in JoM during our first year exemplified some accomplishments of our goals, which are, providing a venue to foster the rapid dissemination of quality research on all aspects of bees, at no cost to the authors, and available online to everyone. Of course these would not have been possible without the help of many people who also believe in the JoM's mission and joined us in this endeavor by kindly cooperating in one or many ways. That includes our families, reviewers, colleagues, editorial staff, publishers, and sponsors. To each of them, we offer our most sincere appreciation.

Our families and colleagues provided constant support and contributed with ideas and solutions to the problems we encountered. More than 30 reviewers from more than 10 countries assured the quality of the papers last year. Each of them took the time and effort to critically and rapidly review each contribution, so we can meet the journal's goals. Such editorial task was facilitated by the open-access platform (Open Journals System) used by the JoM, which is managed by the University of Kansas Libraries. Their support has been critical and greatly appreciated since the time we embarked on the serious effort to build this journal.

According to our statistics, JoM is now being downloaded and frequently visited from more than 76 countries, representing every continent except Antarctica. From the date the journal was launched until 31 December 2013, there were 2302 visits to the JoM site and over 13,000 page views, and users of JoM employed a variety of technologies, mostly traditional desktops (2162 visits) but growingly from mobile devices (92 from smartphones, 48 from tablets). This is gratifying given that we have no invested time or money in advertising the journal. We operate on a budget of $\$ 0$, all of the editorial and production activities representing the voluntary efforts of a small set of individuals (and 95\% of such work is embraced by two people alone!). This permits us to impose nothing on the authors contributing to the journal. Admittedly, this model may not be sustainable as the journal continues to blossom and we are already looking into means for developing an expanded set of 'employees' to maintain the growth of JoM.

As 2014 slowly unfolds before us we are hopeful that this will be an even more exciting year. Already several more papers are in review and the journal continues to gain exposure throughout the world, generating a lot of buzz as papers continue to appear. Help us to keep that buzz loud and clear!

\section{ACKNOWLEDGEMENTS}

We are deeply grateful Brian Rosenblum and Marianne Reed of the University of Kansas Center for Digital Scholarship for their great interest in the Journal of Melittology. Brian was particularly instrumental in not only setting up the journal's website but also in building our relationship with Portico for our independent archiving. Kandy House, Southwestern Oklahoma State University Press, for her continuous help printing the journal when needed. Kellie K. Magill Engel and Amy Comfort de Gonzalez were vital to the success of the journal through their various means of support.

\section{REFERENCES}

Engel, M.S. 2013a. Aristotle's Historia Animalium and Apis reproduction. Journal of Melittology 4: $1-3$.

Engel, M.S. 2013b. A new species of the allodapine bee genus Braunsapis from the Central African Republic (Hymenoptera: Apidae). Journal of Melittology 21: 1-7. 
Engel, M.S. 2013c. Revision of the cleptoparasitic bee genus Cleptommation (Hymenoptera: Halictidae). Journal of Melittology 22: 1-26.

Engel, M.S. 2013d. The bee genus Ischnomelissa in Peru, with a key to the species (Hymenoptera: Halictidae). Journal of Melittology 23: 1-5.

Engel, M.S. 2013e. A new species of Microsphecodes from Peru, with notes on the classification of the genus (Hymenoptera: Halictidae). Journal of Melittology 24: 1-9.

Engel, M.S., \& L.C.V. Breitkreuz. 2013. A male of the bee genus Agapostemon in Dominican amber (Hymenoptera: Halictidae). Journal of Melittology 16: 1-9.

Engel, M.S., \& C.D. Michener. 2013. A minute stingless bee in Eocene Fushan amber from northeastern China (Hymenoptera: Apidae). Journal of Melittology 14: 1-10.

Engel, M.S., \& L. Packer. 2013. A new species of Chiasmognathus from Kazakhstan (Hymenoptera: Apidae). Journal of Melittology 10: 1-7.

Engel, M.S., \& C. Rasmussen. 2013. Revision of the bee genus Chlerogella (Hymenoptera: Halictidae), Part III: New records and a new species from Peru. Journal of Melittology 9: 1-8.

Engel, M.S., V.H. Gonzalez, I.A. Hinojosa-Díaz, \& C.D. Michener. 2013a. Introducing the Journal of Melittology: An outlet for disseminating bee research and raising melittological awareness. Journal of Melittology 1: 1-3.

Engel, M.S., J. Ortega-Blanco, P.C. Nascimbene, \& H. Singh. 2013b. The bees of Early Eocene Cambay amber (Hymenoptera: Apidae). Journal of Melittology 25: 1-12.

Gibbs, J., \& S. Dumesh. 2013. A new species, Lasioglossum (Eickwortia) hienae, from Mexico (Apoidea: Halictidae). Journal of Melittology 13: 1-11.

Gonzalez, V.H. 2013. Taxonomic comments on Megachile subgenus Chrysosarus (Hymenoptera: Megachilidae). Journal of Melittology 5: 1-6.

Gonzalez, V.H., \& M.S. Engel. 2013. Maria Guiomar Nates-Parra: Biographical sketch and summary of contributions to the melittological knowledge of Colombia. Journal of Melittology 6: $1-7$.

Gonzalez, V.H., M.S. Engel, \& P.A. Sepúlveda. 2013a. Taxonomic and biological notes on Andinopanurgus (Hymenoptera: Andrenidae). Journal of Melittology 3: 1-10.

Gonzalez, V.H., C. Rasmussen, \& M.S. Engel. 2013b. Incasarus garciai, a new genus and species of panurgine bees from the Peruvian Andes (Hymenoptera: Andrenidae). Journal of Melittology 8: 1-9.

Gonzalez, V.H., M.S. Engel, \& T.L. Griswold. 2013c. The lithurgine bees of Australia (Hymenoptera: Megachilidae), with a note on Megachile rotundipennis. Journal of Melittology 11: 1-19.

Griswold, T.L. 2013. New Palearctic bee species of Protosmia subgenus Nanosmia (Hymenoptera: Megachilidae). Journal of Melittology 20: 1-9.

Hinojosa-Díaz, I.A. 2013. Presence of Euglossa (Euglossa) amazonica outside of the Amazon Basin - biogeographic insights. Journal of Melittology 2: 1-6.

Michener, C.D. 2013. Notes on male and female facial patterns in bees (Hymenoptera: Apoidea), with comments on other aculeates. Journal of Melittology 26: 1-4.

Montalva, J., J.L. Allendes, \& M. Lucia. 2013. The large carpenter bee Xylocopa augusti (Hymenoptera: Apidae): New record for Chile. Journal of Melittology 12: 1-6.

Rasmussen, C., V.H. Gonzalez, M.S. Engel, \& C.D. Michener. 2013. In memoriam: Wallace Edmund LaBerge (1927-2013). Journal of Melittology 17: 1-22.

Rathor, V.S., C. Rasmussen, \& M.S. Saini. 2013. New record of the stingless bee Tetragonula gressittii from India (Hymenoptera: Apidae: Meliponini). Journal of Melittology 7: 1-5.

Sheffield, C.S., \& J.A. Genaro. 2013. A new species of Megachile (Litomegachile) from Cuba, the Antilles (Hymenoptera: Megachilidae). Journal of Melittology 19: 1-17.

Velez-Ruiz, R.I., V.H. Gonzalez, \& M.S. Engel. 2013. Observations on the urban ecology of the Neotropical stingless bee Tetragonisca angustula (Hymenoptera: Apidae). Journal of Melittology 15: 1-8.

Zambrano-G, G., V.H. Gonzalez, I.A. Hinojosa-Díaz, \& M.S. Engel. 2013. Bees visiting squash (Cucurbita moschata Duchesne et Poiret) in southwestern Colombia (Hymenoptera: Apidae). Journal of Melittology 18: 1-5. 



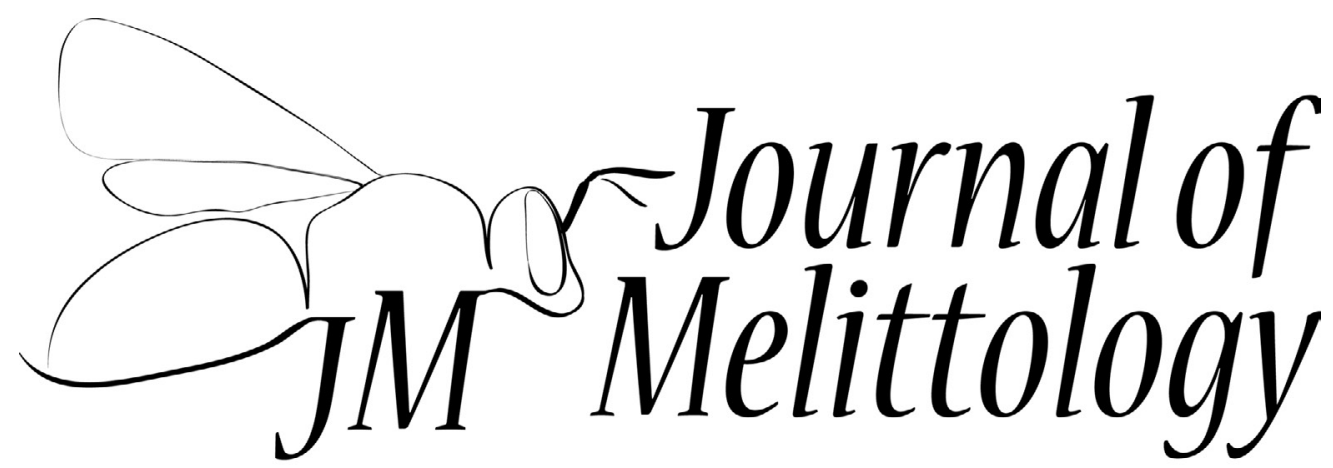

A Journal of Bee Biology, Ecology, Evolution, \& Systematics

The Journal of Melittology is an international, open access journal that seeks to rapidly disseminate the results of research conducted on bees (Apoidea: Anthophila) in their broadest sense. Our mission is to promote the understanding and conservation of wild and managed bees and to facilitate communication and collaboration among researchers and the public worldwide. The Journal covers all aspects of bee research including but not limited to: anatomy, behavioral ecology, biodiversity, biogeography, chemical ecology, comparative morphology, conservation, cultural aspects, cytogenetics, ecology, ethnobiology, history, identification (keys), invasion ecology, management, melittopalynology, molecular ecology, neurobiology, occurrence data, paleontology, parasitism, phenology, phylogeny, physiology, pollination biology, sociobiology, systematics, and taxonomy.

The Journal of Melittology was established at the University of Kansas through the efforts of Michael S. Engel, Victor H. Gonzalez, Ismael A. Hinojosa-Díaz, and Charles D. Michener in 2013 and each article is published as its own number, with issues appearing online as soon as they are ready. Papers are composed using Microsoft Word ${ }^{\circledR}$ and Adobe InDesign ${ }^{\circledR}$ in Lawrence, Kansas, USA.

\section{Editor-in-Chief \\ Michael S. Engel \\ University of Kansas}

\section{Assistant Editors}

Victor H. Gonzalez

Southwestern Oklahoma State University
Charles D. Michener

University of Kansas

Journal of Melittology is registered in ZooBank (www.zoobank.org), archived at the University of Kansas and in Portico (www.portico.org), and printed on demand by Southwestern Oklahoma State University Press. 